\title{
Nipple Deformity
}

National Cancer Institute

\section{Source}

National Cancer Institute. Nipple Deformity. NCI Thesaurus. Code C78503.

A congenital or acquired deformity of the nipple. 